\title{
Podcasting e consumo cultural
}

\author{
Gisela G. S. Castro 1 \\ $\mathrm{ESPM} / \mathrm{SP}$ \\ gcastro@espm.br
}

\begin{abstract}
Resumo: Este artigo apresenta resultados parciais de uma investigação em andamento sobre o consumo de música na Internet. Mais especificamente, trata-se de uma discussão acerca do fenômeno podcasting e suas implicações no engendramento de novas práticas de consumo cultural na cibercultura. Pretende-se refletir sobre a influência dos meios digitais nas modificações em andamento na sensibilidade e cognição humanas. O trabalho examina os usos do podcasting, tanto do ponto de vista do produtor quanto do usuário, analisando suas possíveis continuidades e descontinuidades com mídias tradicionais, bem como as especificidades que vêm contribuindo para consolidar a crescente popularidade desta prática na cena contemporânea.
\end{abstract}

Palavras-chave: podcasting, cibercultura, comunicação, consumo cultural

\begin{abstract}
This paper presents partial results of ongoing research project on the consumption of music over the Internet. More specifically, it discusses podcasting and its implications in the emergence of new cultural consumption practices within cyberculture. It is also our purpose to reflect upon on the influence of digital media in the ongoing modifications on human sensibility and cognition. The article examines the uses of podcasting, from producers' and users' points of view, analyzing its possible continuities and discontinuities with traditional media, as well as the specific aspects that contribute to consolidade the growing popularity of such practice in the contemporary cultural scene.
\end{abstract}

Keywords: podcasting, cyberculture, media studies, cultural consumption

\footnotetext{
${ }^{1}$ Doutora em Comunicação e Cultura (ECO-UFRJ) e docente do programa de mestrado em Comunicação e Práticas de Consumo ESPM, São Paulo. Desenvolve pesquisa sobre o consumo de música na Internet. Membro da coordenação editorial da revista Comunicação, Mídia e Consumo.
} 
Resumen: En este artículo se presentan los resultados parciales de un estudio, todavía en curso, sobre el consumo de música por Internet. Más específicamente, se trata de una discusión sobre el fenómeno podcasting y la aparición de nuevos hábitos de consumo cultural en la cibercultura. Se pretende reflexionar sobre la influencia de los medios digitales en las modificaciones que están produciéndose en la sensibilidad y la cognición humanas. El trabajo examina los usos del podcasting, tanto desde el punto de vista del productor como del usuario, analizando sus posibles continuidades y discontinuidades con los media tradicionales, así como las especificidades que están contribuyendo a consolidar su creciente popularidad en el escenario contemporáneo.

Palabras-clave: podcasting, cibercultura, comunicación, consumo cultural

Résumé: Cet article présente résultats partiels d'une recherche en cours au sujet de la consommation de musique sur internet. Il s'agit, plus spécifiquement, d'une discussion autour du phénomène de podcasting et ses implications dans le surgissement de nouvelles pratiques de consommation culturelle dans la cyberculture. Nous avons également l'intention de réfléchir à propos de l'influence des moyens digitaux en ce qui concerne les modifications sur la sensibilité et la cognition humaines. L'étude examine l'utilisation du podcasting du point de vue de ceux qui publient sur le Web les fichiers, les producteurs, et aussi de la perspective des utilisateurs, qui les cherchent, tout en analysant les continuités et discontinuités par rapport aux médias traditionnels, ainsi que les spécificités qui contribuent à solidifier la croissante popularité de cette pratique dans le scénario contemporain.

Most-clés: podcasting, cyberculture, communication, consommation culturelle 


\section{Para começar:}

A Internet se configura hoje como uma das mais importantes ferramentas de comunicação global. A compressão espaço-temporal propiciada pela quase instantaneidade dos fluxos eletrônicos favorece a instauração de significativas novas práticas e experimentações no contexto que se convencionou chamar de cibercultura (LEMOS, 2002; LÉVY, 1999; RÜDIGER, 2002). O podcasting, enfocado neste artigo, apresenta-se como um fenômeno típico da fase atual dessa cultura. O presente artigo pretende examinar essa prática nascente, tendo em vista o conjunto de possíveis transformações em curso nas formas de escuta e consumo cultural.

Walter Benjamin fornece importantes elementos no seminal texto "A obra de arte na era de sua reprodutibilidade técnica” para a compreensão da experiência relativa aos produtos culturais típicos da cultura de massas. Nesse estudo, o mais jovem membro da Escola de Frankfurt constata que a crescente mediação dos áudio-visuais estaria ensejando uma notável reconfiguração nos esquemas perceptivos. Entendendo a percepção como base do sistema cognitivo, aponta-se hoje para as complexas ressonâncias advindas das transformações perceptivas operadas pelos meios digitais.

Aprendemos com McLuhan (1992) que os meios participam da configuração dos esquemas cognitivos de seus usuários. Sabemos que nossas subjetividades em grande parte passaram a ser constituídas pelas mídias. Da mesma forma, estamos conscientes de que o desenvolvimento das mídias está diretamente ligado aos diferentes modos de apropriação social aos quais estão sujeitas (CASTELS, 2003). Considerando-as como parte integrante dos mecanismos de modelização social, evita-se o equívoco de reificá-las, caindo em um determinismo tecnológico com o qual não concordo. Importa aqui observar o papel desempenhado pelas tecnologias de informação e comunicação no conjunto de dispositivos de modulação subjetiva com os quais interagimos. 
Conforme observa André Lemos (2002:113), "as tecnologias marcam profundamente a totalidade do corpo social através dos modos de produção e consumo, das formas de comunicação e da normalização da vida social”. Devido ao permanente processo de negociação entre antigas e novas tecnologias que caracterizam a cultura urbana contemporânea, cabe frisar que não costumo adotar visões substantivas que pensam a cibercultura em ruptura com o processo histórico-social que antecede a emergência das novas tecnologias de informação e de comunicação.

Uma análise mais detalhada das transformações nas formas de escuta operadas pela entrada em cena de tecnologias como o telefone, o fonógrafo e o microfone, por exemplo, pode ser encontrada em trabalho anterior meu (CASTRO, 2003). Para efeitos da discussão pretendida aqui, importa ressaltar a importante reconfiguração dos sentidos como decorrência da intensa modificação dos meios de produção, distribuição e consumo que marcam a cultura capitalista pós-industrial.

Tomando a música como objeto de investigação na análise das transformações nas formas de escuta, embora a experiência de ouvir execuções ao vivo não tenha perdido sua importância, a gravação há décadas deixou de ser considerada menor ou inautêntica, sendo mesmo tomada como matéria prima para a produção de certos gêneros musicais atuais como, por exemplo, o hip hop e a música eletrônica. De fato, desde a segunda metade do século passado o boom da indústria fonográfica incentivado pelos diferentes meios de comunicação e favorecido pela flagrante miniaturização das aparelhagens de som tornou a prática de ouvir música cada vez mais disseminada no quotidiano de grandes parcelas das populações do planeta. Paralelamente, destaca-se a onipresença dos telefones celulares e dos fones de ouvido dos mais variados aparelhos portáteis que já fazem parte do vestuário urbano atual. Finalmente, a ubiqüidade dos potentes sistemas de som de 
automóveis e residências redesenha a ambiência sonora bem como a nossa escuta.

A plasticidade das tecnologias digitais e as possibilidades abertas pela microinformática vêm contribuindo para modificar ainda mais radicalmente as formas de escuta ao tornar difusas as fronteiras entre consumidores e produtores, autores e editores, ouvintes e distribuidores, original e cópia. Nesse sentido, penso ser importante discutir a influente presença dos meios digitais como vetores na constituição de novas práticas de produção e consumo cultural, bem como sua contribuição para uma eventual reconfiguração do sensório e do imaginário urbano atual.

Neste cenário, destacam-se os telefones celulares digitais e os players portáteis de $\mathrm{MP}_{3}$, dentre os quais o já consagrado iPod. Os fones de ouvido há tempos promovem a imersão do ouvinte em ambientes acústicos personalizados e exclusivos. Por seu turno, novas gerações de celulares configuram-se como aparelhos multifuncionais que vêm se tornando instrumentos de inclusão digital. O custo reduzido desses aparelhos se comparado ao de um computador pessoal os leva a poder funcionar como portas de entrada para muitos usuários que antes não tinham acesso à Internet (PELLANDA, 2005), agregando uma plêiade de funções adicionais à telefonia. Finalmente, os players portáteis permitem ao usuário o acesso a suas coleções particulares de música, agora medidas em gigabytes, a qualquer hora e em qualquer lugar.

\section{Sobre iPods e Podcasting}

Um dispositivo como o iPod pode ser utilizado com fones de ouvido ou conectado ao sistema de som dos automóveis, por exemplo, funcionando em ambos os casos como uma estação rádio portátil e particular. Além de faixas de música, pode-se ainda estocar e ouvir programas de podcast, blogs de áudio que começam a proliferar muito rapidamente na web. O iTunes da Apple ajudou a tornar popular o podcasting ao incorporar em suas versões 
mais recentes softwares agregadores que organizam os conteúdos dos podcasts, além de disponibilizar um catálogo dos podcasts mais populares a partir de maio desse ano.

O podcasting (nome que mistura iPod com broadcast, ou transmissão) funciona através de um sistema geralmente gratuito de assinaturas, no qual um software de rastreamento e atualização automática (que funciona através do sistema RSS - real simple syndication, já utilizado para arquivos de texto) garante que o usuário esteja sempre em dia com os novos lançamentos. Um aficionado por computador e ex-VJ da MTV, o inglês Adam Curry, apelidado de "podfather", destaca-se como um dos mais conhecidos pioneiros desta prática que já saiu do underground e rapidamente vem ganhando o mainstream da cibercultura. Credita-se a veloz proliferação do fenômeno podcasting ao apoio dado pelo todo-poderoso Steve Jobs, da Apple, que qualificou esta nova mídia como o "rádio do futuro" (NUCCI, 2005).

Pode-se observar que o iPod vem se tornando um must ao congregar algumas obsessões do consumo contemporâneo tais como o fascínio do exclusivo, do design arrojado, up to date, da miniaturização (portabilidade) e do gigabyte. De fato, o "estar em dia” com produtos de última geração cujas capacidades de armazenamento seriam absurdas até pouco tempo parece ser um valor em alta no imaginário social atual. Também se valoriza sobremaneira a aquisição de produtos que projetem uma imagem de elevado status em um meio onde o consumo funciona como um importante codificador social (ROCHA, 2004; McCRACKEN, 2003). Neste sentido, é exemplar que uma empresa como a BMW tenha sido a primeira a oferecer de fábrica à sua seleta clientela a ligação do iPod ao rádio do carro. Hoje, quando esta tecnologia já começa a ser copiada por outros fabricantes, ela segue inovando oferecendo como possibilidade a ligação direta entre dois BMWs através de podcasting. 
Embora não seja exclusivo do iPod, podendo ser baixados nos computadores pessoais, laptops, notebooks, palms e em outros tipos de players portáteis que não os diversos modelos da Apple, o podcasting pode ser entendido como um produto da nova fase da cibercultura, marcada pela mobilidade das tecnologias wireless. A prática dos blogs e fotologs já está estabelecida. Através dessas páginas de conteúdo personalizado, novas formas de sociabilidade vêm à tona, sendo a interatividade favorecida quando receptores são estimulados a postar nos blogs seus comentários e impressões, propiciando uma troca mais direta entre autores (de blogs) e seu público. No meio corporativo, verifica-se que diversas empresas também adotam o formato para estabelecer comunicação mais ágil com fornecedores e clientes.

Dispensando os grandes estúdios de rádio e complexos aparatos técnicos para viabilizar sua produção, os blogs de áudio podem ser dedicados, por exemplo, a determinados subgêneros de música, nichos minoritários de consumo que não encontram espaço na programação massificada das rádios comerciais. Sendo assim, arquivos musicais raros podem ser disponibilizados em formato MP3 e transmitidos em podcast, utilizando-se o sistema RSS de assinaturas. Nesses casos o autor pode ser denominado um WebDJ, o repertório como uma das marcas registradas dos melhores DJs, seja em que meio atuem.

Além dos programas dedicados à música, há ainda podcasts sobre tópicos específicos como vinhos, cinema, política, etc. Alem disso, alguns programas de rádio tradicional passaram a ser oferecidos também como podcast. Nesse caso a Internet é utilizada como um canal alternativo de distribuição de modo a cativar novos ouvintes. A BBC foi uma das pioneiras no novo formato, apostando na viabilidade do podcasting comercial. Entre nós, algumas rádios brasileiras também já experimentam com o novo formato. $\mathrm{O}$ podcasting funciona de maneira parecida com as netradios ou as rádios via satélite, sendo o sistema de distribuição por meio de assinaturas RSS o seu 
maior diferencial. Essa inovação de certa forma inverte o sentido do fluxo um $\rightarrow$ muitos, característico dos meios de comunicação massivos. Nesse caso seria mais apropriado dizer que o fluxo funciona segundo o esquema muitos $\rightarrow \mathrm{um}$. Sendo assim, trata-se de uma tecnologia por meio da qual o conteúdo é "retrirado" (pull) pelo assinante ao invés de ser "empurrado" (push) até ele por um canal aberto de distribuição. O conteúdo que se recebe é o programa completo, ou o episódio completo daquele programa; algo que se pode guardar para ouvir quando e onde quiser.

Convém lembrar ainda que, ao contrário do que ocorre com as freqüências de rádio, não há regulamentação ou necessidade de concessão de canal para transmissões em podcasting. Considerando que seu lançamento não tem ainda nem 1 ano, rapidamente do Vaticano ou da NASA ao mundo pop, muitos são os adeptos desta nova modalidade de geração e distribuição de conteúdo na rede.

Dentre os interessantes usos do podcasting, destacam-se visitas guiadas em museus e centros culturais. Além de tours oficiais já produzidas em podcasts com chancela institucional, surgem versões alternativas, não autorizadas, postadas na $W e b$ por professores ou estudantes de arte que oferecem seus comentários em podcast (KENNEDY, 2005). Destaco ainda, dentre as inúmeras outras modalidades de podcasting disponíveis na Internet, os personal trainers digitais. Estes são podcasts programados com música, mensagens de estímulo e orientação dirigidas ao praticante de atividades físicas em suas sessões de exercícios. Tais programas podem agregar ainda pequenos spots comerciais relativos ao mercado fitness, como por exemplo anúncios de bebidas energéticas ou barras de cereais. Finalmente, se os audio-books não chegaram a ser o sucesso comercial que prometiam, parece provável que passemos a conviver em breve com leituras dramatizadas dos mais variados títulos, oferecidas on demand em formato podcast... 


\section{Podcasting na blogosfera}

O podcasting parece ser consoante com as principais características do que já se convencionou denominar "blogosfera", cuja praticidade, informalidade, espontaneidade e interatividade têm levado legiões de internautas a decidir gerar e distribuir seu próprio conteúdo, disponibilizado em blogs, fotologs, audiologs e videologs abertos à visitação pública. O próprio criador da world wide web, Tim Berners-Lee, identifica no blogging a realização de uma das mais importantes vocações da $w e b$, ou seja, congregar conteúdo gerado pelos próprios usuários, estimulando a interatividade (LAWSON, 2005). O rápido crescimento deste tipo de prática parece apontar para um certo esgotamento de formas mais tradicionais e lineares de comunicação através do clássico esquema um $\rightarrow$ muitos. A descentralidade da rede costuma ser apontada como um dos seus principais diferenciais em relação a outras mídias. Devido ao seu modo próprio de operação, cada pólo final pode em tese funcionar tanto como um pólo receptor quanto como um pólo emissor de conteúdo, gerando uma trama reticular do tipo muitos $\leftrightarrow$ muitos (SODRÉ, 2002).

No entanto, sabemos ser ingênuo supor que haja uma real e efetiva equivalência e permutabilidade entre emissores e receptores na maior parte do sempre crescente número de nós da Web. Dificuldades técnicas e precariedade de infra-estrutura contribuem para afastar muitos usuários em potencial das diversas modalidades de geração de conteúdo online. A limitada familiaridade com as linguagens informacionais atuais dificulta o manejo de programas de software de geração de conteúdo, embora estes estejam se tornando cada vez mais user-friendly. O custo elevado do acesso à banda larga de transmissão de dados também tem sido apontado como responsável por afastar outros possíveis candidatos desta prática. No caso específico do podcasting, embora arquivos de áudio sejam muito menos pesados do que os de imagem (fotos, vídeos), por exemplo, a banda larga ainda é necessária para 
facilitar e acelerar o download e viabilizar a produção e distribuição dos podcasts.

Com tudo isso, cresce exponencialmente o número de adeptos da blogosfera, que já se configura também como um meio de negócios. Destaquese aqui o efeito-novidade que torna mais significativo o podcasting como fenômeno viral. Dentre os inúmeros exemplos de utilizações possíveis desta modalidade midiática, bandas se servem de portais especializados como um canal mais direto de contato com os fãs, podendo disponibilizar faixas de música em formato MP3 para download ou distribuir esse conteúdo através de podcasts que o usuário recebe diretamente no seu terminal, podendo carregar no bolso e ouvir quando e onde desejar. Surgem empresas prestadoras de serviços para essa indústria recente, unindo o lúdico e social ao comercial e corporativo.

\section{Podcasting e Multi-tasking}

Importante destacar uma outra característica do podcasting que o torna atraente para um tipo de público que já se habituou ao que estudiosos norte-americanos denominam multi-tasking, ou seja, a um tipo de concentração difusa que permite que se execute diferentes tarefas simultaneamente, tais como ouvir música, fazer o dever de casa no computador, conversar com um amigo online enquanto fala ao telefone com outra pessoa.

No início desse texto, chamei a atenção para as modificações na percepção deflagradas pelos meios áudio-visuais, tal como apontadas por Walter Benjamin. Mais adiante, mencionei uma possível reconfiguração do sensório e do padrão cognitivo deflagrada também pelos meios digitais. $\mathrm{O}$ multi-tasking, esta capacidade de se concentrar em diversas tarefas ao mesmo tempo, parece ser um sintoma de uma mudança cognitiva que teria os meios digitais como facilitadores. Ao dirigir-se primordialmente à escuta - e não à visão - o podcasting apresenta dentre suas principais vantagens deixar seus 
usuários livres (ao menos em tese) para simultaneamente executar diferentes outras tarefas como, por exemplo, dirigir um automóvel ou pedalar uma bicicleta.

A onipresença dos fones de ouvido, freqüentemente apontada em meu trabalho e já mencionada neste breve artigo, também sinaliza para formas de escuta compatíveis com este tipo de cognição multifuncional, além de habituar o ouvinte a encapsular-se em uma ambiência sonora personalizada e sob medida enquanto executa suas múltiplas atividades. Penso que o podcasting pode ser compreendido dentro desta mesma linhagem de tecnologias que favorecem a customização do conteúdo por via aural, liberando a visão para outras tarefas que, com freqüência, são desempenhadas simultaneamente.

\section{Vlogs, vodedasting e o novo iPod video}

Numa cultura extremamente visual como a nossa, o apelo da imagem se faz presente também como prolongamento da escuta. No caso da música, há tempos já se convive com video-clips, inaugurados pelos Beatles nos anos sessenta do século XX e transformados em parte integrante dos principais lançamentos comerciais a partir dos anos oitenta. O sucesso comercial da MTV, cuja programação inicialmente era dedicada exclusivamente aos vídeos de música, os quais foram se tornando cada vez mais elaborados, também aponta para uma evidente consolidação da experiência de "ver" ou "assistir" música na cultura midiática.

No troca-troca que caracteriza as redes peer to peer, ou par a par, incontáveis usuários compartilham arquivos de áudio, fotos e vídeo, estes últimos especialmente favorecidos por dois fatores principais: de um lado, o crescente aumento da largura de banda de transmissão de dados e, por outro lado, o surgimento de formatos de compressão cada vez mais eficazes em reduzir o tamanho dos arquivos, com baixo prejuízo de qualidade. 
Tendo em vista a geração e compartilhamento de conteúdo personalizado que dá origem à já mencionada "blogosfera", observa-se que a crescente proliferação de câmeras digitais e webcams no mercado propicia a criação de vlogs, ou video logs. Funcionando dentro dos mesmos princípios que os demais tipos de blogs, este novo formato se agrega aos já existentes tendo como principal diferença a oferta de seqüências de imagens gravadas em vídeo. Para o usuário comum, sem acesso a esquemas de distribuição profissional, essa prática se torna viável por existem diferentes tipos de software de código aberto (open source) que comprimem os dados encriptados e os disponibilizam para distribuição mais fácil através de video podcasting. Atento à novidade, o iTunes Music Store começa a oferecer vídeos de música, programas de TV e trailers de filmes comerciais pelo sistema de video podcasting. Complementando a novidade, o lançamento do último modelo do iPod em outubro de 2005. Equipado com tela de vídeo de alta resolução, o mais novo iPod permite a complementaridade entre as experiências de ver e ouvir música, assim como assistir filmes caseiros e video podcasts. A distribuição de filmes comerciais via Internet poderá eventualmente representar uma importante fatia do mercado.

\section{Podcasting como mídia negocial}

No que tange às possíveis aplicações comerciais da tecnologia de podcasting, podemos observar modelos nascentes de negócios tais como o patrocínio comercial em podcasts (de áudio ou vídeo) mais populares, nesse caso remunerando os responsáveis pelos programas, os quais podem continuar sendo distribuídos gratuitamente ou podem ser comprados através de lojas virtuais como o iTunes, o novo Napster e outras que vêm contribuindo para disseminar a prática do download comercial e o sistema de assinaturas pagas, "ensinando" o usuário a consumir conteúdo distribuído de forma legalmente sancionada pela indústria cultural. 
Dentre os principais atrativos desta nova modalidade midiática, destacam-se, do lado do usuário, a escuta personalizada com conteúdo à la carte servido em seu próprio player ou terminal, dispensando-o da necessidade de navegar em busca desse conteúdo. Do lado do produtor, o compartilhamento, pedra de toque da cibercultura (ver CASTRO, 2005 b), bem como a possibilidade de seu podcast gerar renda. Do lado do patrocinador ou produtor corporativo, a forte segmentação de audiência e a vantagem de funcionar através de um serviço de assinatura no qual o cliente recebe o conteúdo que escolheu receber, podendo ouvi-lo quando e onde desejar. Dessa forma, os podcasts estão livres de spams, aquelas mensagens indesejadas recebidas através de serviços de correio eletrônico (email). A idéia é que ouvintes de podcasts estariam predispostos a receber de bom grado o conteúdo oferecido, já que baixam o que é conhecido.

No mundo corporativo, o podcasting começa a funcionar também como tecnologia preferencial para cobertura de eventos; para geração de conteúdo técnico específico utilizado em diversos programas de treinamento dentro e fora da empresa, e ainda para comunicação interna. Empresas especializadas oferecem consultoria e serviços, em muitos casos funcionando também como portais de podcasting.

\section{Para concluir}

A crescente pregnância do ciberespaço no quotidiano de parcelas significativas das populações, especialmente nos centros urbanos, evidencia a relevância dos estudos da cibercultura. Sabendo ser o ciberespaço cenário instável, imprevisível e rico em experimentações, cabe ressaltar a decisiva importância da apropriação social de tecnologias nascentes na própria constituição de novas esferas das vidas pública e privada. No contexto geral dos desdobramentos psicossociais e socioculturais das novas tecnologias de informação e comunicação, contexto no qual o tema das cibercidades vem ganhando destaque, talvez seja precipitado pretender tirar conclusões acerca 
de um fenômeno como o podcasting, especialmente tão recente entre nós, ainda mais no que se refere à previsão ingenuamente premonitória de que ele estaria substituindo o rádio tradicional.

Parece mais correto pensar o podcasting como versão "blogueira" do rádio, oferecendo conteúdo customizado on demand, coerente com a tendência de forte segmentação das audiências favorecida pelos meios eletrônicos. Sendo assim ele pode conviver lado a lado com o rádio como nós o conhecemos, do mesmo modo que se verifica que o correio eletrônico não tornou obsoleto o correio tradicional.

Quanto ao video podcasting, ou vodcasting, penso que seu principal atrativo seria o de se alinhar à tendência de democratização da geração de conteúdo na $W e b$. Se antes estávamos restritos a receber e assistir vodcasts apenas nas telas do computador, portanto sem a portabilidade que, como vimos, vem se tornando um must do consumo high tech contemporâneo, recentes lançamentos como o novo iPod video solucionam esta questão. Apresentando-se como "música para os olhos", o mais recente membro da seleta e crescente tribo dos iPods parece ter tudo para se tornar o novo “queridinho" de descolados endinheirados. Entretanto, é cedo para especular se irá ser adotado como um gadget de alcance massivo. Mais importante ainda para fins da discussão aqui proposta, seria difícil no momento precisar que papel lhe caberá desempenhar nas transformações em curso nos modos de percepção e cognição.

A Internet, que se consolidou como um meio eminentemente textual em seus primeiros tempos, se torna um ambiente onde cada vez mais as funções de ver (nesse caso, assistir) e ouvir vão substituindo as funções de ler e escrever. Para capturar a sempre fugaz atenção dos internautas, conteúdos são oferecidos em formatos atraentes, palatáveis e de forma cada vez mais amigável, sem importunar o usuário ou exigir dele maiores esforços. Ademais, a interatividade tem como contrapartida o favorecimento da cooperação 
indispensável quando se está diante de tarefas cujos níveis de complexidade exigem cognição distribuída entre humanos e máquinas, bem como entre diferentes indivíduos transformados em nós da Web (LÈVY, 1999; MARKOFF, 2005).

Pensando na grande quantidade de jovens disléxicos com notória dificuldade para dominar a leitura e a escrita mas que costumam obter excelentes resultados com teclados e telas dos computadores e games eletrônicos, e pensando também nos inúmeros casos de déficit de atenção (DDA) que engrossam as estatísticas escolares mais recentes, podemos especular que estes seriam indícios de modificações de maior magnitude na sensibilidade e na cognição humanas promovidas pela intensa convivência com os fluxos eletrônicos dos meios digitais.

Os ritmos da leitura e o da escrita diferem do imediatismo da escuta e da visão. Ininterruptos, estes últimos se dão através de associações ouvidocérebro ou olho-cérebro que funcionam através de recortes perceptivos processados com extrema rapidez. Leitura e escrita utilizam áreas e processos cerebrais diferentes, exigindo complexa integração entre diversas estruturas corticais, motoras e sensoriais. Talvez, conforme a intuição de McLuhan, estejamos assistindo ao ocaso de modelos perceptivos e cognitivos moldados por longa tradição de leitura e escrita, sendo os meios audiovisuais responsáveis pelo surgimento de novas configurações subjetivas.

A inegável plasticidade dos meios digitais e sua forte tendência em afastar-se do modelo textual inicial em direção a modelos áudio-visuais interativos parecem reforçar a primazia do ver e ouvir em detrimento do ler e escrever, ainda que naturalmente essas competências sigam sendo bastante valorizadas culturalmente. Embora aliada aos que acompanham e percebem as mudanças em curso, devo ressaltar que não me alinho com visões catastróficas que aludem a insondáveis perigos, e nem com o ingênuo e acrítico saudar das benesses da "nova era" que se descortina. 
Sem oferecer certezas estáveis ou conclusões apressadas, este breve artigo pretendeu enfocar e analisar o podcasting no conjunto das novas formas de consumo cultural favorecidas pelos meios digitais. A reflexão aqui proposta visa integrar o tema nas discussões acerca das mediações tecnológicas e transformações do sujeito que hoje perpassam o fascinante campo da Comunicação.

\section{Referências:}

AXLINE, Keith (2005). iPods for Anarchists. In: Wired News, boletim eletrônico, edição 27 de setembro.

BEITH, Malcolm (2005). The Beat Goes On. In: Revista Newsweek, Reportagem Especial, Edição 26 setembro a 3 de outubro.

BENJAMIN, Walter (1987). Obras Escolhidas. Vol. 1. Magia e Técnica, Arte e Política. São Paulo: Brasiliense.

BRIGGS, Asa e BURKE, Peter (2004). Uma história Social da Mídia: de Gutenberg à Internet. Rio de Janeiro: Jorge Zahar.

CASTELS, Manuel (2003). A Galáxia da Internet: reflexões sobre a Internet, os negócios e a sociedade. Rio de Janeiro: Jorge Zahar.

CASTRO, Gisela (2003). As Canções Inumanas: música, tecnologia, escuta \& comunicação. Tese de Doutorado. Programa de Pós-Graduação em Comunicação e Cultura. Escola de Comunicação, Universidade Federal do Rio de Janeiro.

(2004). Novas posturas de escuta na cultura contemporânea. In: Porto Alegre, UFRGS, Revista eletrônica Intexto, $\mathrm{n}^{0} 10$.

(2004b). Web Music: produção e consumo de música na cibercultura. In: São Paulo, ESPM, Revista Comunicação, Mídia e Consumo, n॰2. COMPÓS, $\mathrm{n}^{\mathrm{o}} 2$.

(2005). As Canções Inumanas. Revista eletrônica e-

(2005b). Web Music: música, escuta e comunicação. In: São Paulo, Revista Brasileira de Ciências da Comunicação (RBCC - Intercom), vol. XXVIII, $\mathrm{n}^{\mathrm{o}}$ 1, janeiro a julho. 
DOTINGA, Randy (2005). TV Tries Shaky Hand at Podcasting. In: Wired News, boletim eletrônico, edição 15 de abril.

FRIES, Steve (2005). ITunes Mints Podcasting Stars. In: Wired News, boletim eletrônico, edição 18 de julho.

(2005). Podcasting Goldrush Is On. In:Wired News, boletim eletrônico, edição 27 de setembro.

KAHNEY, Leander (2005). Apple Gives Video the IPod Touch. In: Wired News, boletim eletrônico, edição 12 de outubro.

KENNEDY, Randy (2005). With Irreverence and an iPod, Recreating the Museum Tour. Jornal The New York Times, edição 28 de maio.

LAWSON, Mark (2005). Berners-Lee on the read/write web. Entrevista transmitida pela rádio BBC e disponível em BBC News, boletim eletrônico, edição 9 de agosto.

LEADBEATER, Charles (2005). Somos todos inventores. In: São Paulo, Revista Carta Capital, edição de 6 de julho.

LEE, B. J. (2005) Wired at Any Price. In: Revista Newsweek, Reportagem Especial, edição 26 de setembro a 3 de outubro.

LEMOS, André (2002). Cibercultura: tecnologia e vida social na cultura contemporânea. Porto Alegre: Sulina.

LÉVY, Pierre (1999). Cibercultura. Rio de Janeiro: Editora 34.

LINS, Daniel. (org.) (1997) Cultura e Subjetividade: saberes nômades. Campinas: Papirus.

MARKOFF, John (2005). Web Content by and for the Masses. In: Wired News, boletim eletrônico, edição 25 de junho.

MARTINS, Francisco M. e MACHADO DA SILVA, Juremir (orgs.) (2004). A Genealogia do Virtual: comunicação, cultura e tecnologias do imaginário. Porto. Alegre: Sulina.

McCRACKEN, Grant. Cultura e consumo. Rio de Janeiro: Mauad, 2003.

McLUHAN. Marshall (1992). Understanding media: the extensions of man. Cambridge: MIT Press.

MCNICOLL, Tracy (2005). A World of Digital Dim Sum. Revista Newsweek, Reportagem Especial, Edição 26 setembro a 3 de outubro.

MILLER, Karen Lowry (2005). Jukebox Junkie. In: Revista Newsweek, Reportagem Especial, edição 26 de setembro a 3 de outubro.

NUCCI, João Paulo (2005). A ruidosa revolução do podcasting. In: São Paulo, Revista Meio \& Mensagem, edição 4 de julho. 
PELLANDA, Eduardo C. (2005). O "local" do virtual no ambiente de Internet móvel. In: ANAIS Intercom, NP Tecnologias da Informação e Comunicação.

PEPPER, Tara (2005). Making Their Own Breaks. In: Revista Newsweek, Reportagem Especial, edição 26 setembro a 3 de outubro.

QUAIN, John (2005). Now, Audio Blogs for Those Who Aspire to Be D.J.'s. In: Jornal The New York Times, edição 12 de maio.

ROCHA, Everardo (2004). Comunicação, troca e classificação: notas para uma pesquisa do consumo como sistema cultural. In: PEREIRA, Miguel; GOMES, Renato Cordeiro e FIGUEIREDO, Vera Follain (orgs.) Comunicação, representação e práticas sociais. Rio de Janeiro: Ed. PUCRio; Aparecida, SP: Idéias \& Letras.

RÜDIGER, Francisco (2002). Elementos para a crítica da cibercultura: sujeito, objeto e interação na era das novas tecnologias de comunicação. São Paulo: Hacker Editores.

SODRÉ, Muniz (2002). A Antropológica do Espelho: uma teoria da comunicação linear e em rede. Petrópolis: Vozes.

\section{Websites consultados (em ordem alfabética):}

www.apple.com/itunes (acesso semanal de abril a outubro de 2005)

www.bbc.com (acesso em agosto e outubro de 2005)

www.bmw.com (acesso em outubro de 2005)

www.ipodder.org (acesso em setembro e outubro de 2005)

www.nytimes.com (acesso diário de março a outubro de 2005)

www.podcastingbrasil.com.br (acesso em agosto e setembro de 2005)

www.wikipedia.org (acesso em setembro e outubro de 2005)

www.wired.com (acesso semanal de abril a outubro de 2005) 